\title{
Kebutuhan Afiliasi Siswa
}

\author{
Angraini Puspita Sari ${ }^{1}$, Neviyarni $\mathrm{S}^{2}$, Ifdil Ifdil ${ }^{3}$ \\ ${ }^{123}$ Universitas Negeri Padang \\ $\fallingdotseq$ e-mail: anggrainipuspitasari@gmail.com
}

\begin{abstract}
This study describes the needs of student affiliation. Affiliate needs are a need for good relationships with others. Affiliate needs are necessary in every individual, students. Students who in adolescent development direly need affiliate needs. This is because one task of adolescent development is to foster good relationships with same-sex and opposite types. This is important to be known and fulfilled by students. This article aims to describe the needs of student affiliation based on aspects: 1) get closer, 2) cooperate, 3) make happy, 4) seek affection, and 5) stay loyal to friends. The research used in this study is a descriptive type, with a sample of 271 students. The instrument used is inventories affiliate needs. Data analysis used is percentage technique. The results of the study revealed that the need for student affiliation based on aspects of getting closer, cooperating, making fun and staying loyal to friends students were in the medium category and the need for affiliation of students based on looking for affection was in the high category. These results show that there are still students who have not met the needs of their affiliates. Therefore, the role of BK teachers is needed in helping students to meet their needs.
\end{abstract}

Keywords: Needs, Affiliation

\section{PENDAHULUAN}

Remaja memiliki tugas perkembangan yang harus dipenuhi dan tercapai dalam beberapa tahap perkembangannya. Siswa SMP berada pada masa remaja awal, dengan rentangan usianya yaitu 12-15 tahun. Siswa SMP yang berada masa remaja awal mengalami masa perubahan awal sehingga ia memerlukan perhatian, dukungan dan pengetahuan mengenai remaja dalam mencapai tugas perkembangannya. Pada masa ini juga sering terjadi perubahan suasana hati (Taufik, Ifdil \& Ardi, 2013), selain itu beberapa dampak negatif lain juga sering terjadi disebabkankan tidak tercapainya tugas perkembangan, diantaranya konsep diri negatif (Reski, Taufik, \& Ifdil, 2017; Thanoesya, Syahniar, \& Ifdil, 2016), kurang percaya diri (Fitri, E., Zola, N., \& Ifdil, I., 2018), mengalami gangguan psikologis seperti stres (Barseli, Ifdil, \& Nikmarijal, 2017; Sandra, \& Ifdil, 2015; Zola, Fadli, \& Ifdil, 2018; Alizamar, dkk, 2018; Wardi, \& Ifdil, 2016; ) dan kecemasan (Annisa, \& Ifdil, 2016). Apabila tugas-tugas perkembangan ini terpenuhi maka individu akan merasakan kepuasaan, kebahagian, dan penerimaan lingkungan (Karneli, 2018). Pada masa remaja banyak terjadi perubahan dalam diri siswa, seperti perubahan kognitif dimana siswa semakin berpikir lebih komplek, perubahan emosional yang menjadi sensitif, perubahan sosial yang mana siswa akan lebih sering menghabiskan waktu untuk berkumpul bersama teman-teman (Ifdil, Denich, \& Ilyas, 2017). 
Pada masa ini individu berada pada tahap perkembangan kematangan fisik, emosional, sosial, dan mental (Khaira, Firman, \& Neviyarni, 2017). Salah satu tugas perkembangan yang harus dipenuhi siswa ialah tugas perkembangan sosial (Ardi, Ibrahim, \& Said, 2012). Dimana siswa akan cenderung membina hubungan baik dengan orang lain dan diterima oleh orang lain. Membina hubungan baik dan diterima oleh orang lain ini disebut dengan kebutuhan afiliasi. Kebutuhan afiliasi sejalan dengan salah satu tugas perkembangan remaja yaitu membina hubungan yang lebih matang dengan orang lain baik dengan sesama jenis ataupun yang berlawanan jenis.

Kebutuhan afiliasi akan memberikan pengaruh terhadap tingkah laku remaja. Hal ini membuat siswa mampu menunjukkan energi dalam menyelesaikan tugas-tugas akademik, mengembangkan hubungan sosial, memperoleh penghargaan dan penerimaan dari lingkungannya serta meningkatkan kemampuan, karena siswa termotivasi untuk memenuhi dan meminimalisir kekurangan yang ada pada dirinya (Purwadiningsih, 2016). Siswa yang memiliki kebutuhan afiliasi menurut Muray (dalam Hall \& Lindzey, 2005:36) akan memenuhi aspek mendekatkan diri yang mengarah kepada kedekatan siswa dengan orang lain, bekerjasama berarti memiliki respon baik dari orang lain yang mengarah kepada mencapai tujuan bersama, membuat senang orang lain berarti menyenangkan orang lain dengan menunjukkan sikap yang peduli, dll, mencari afeksi berarti mencari cinta dan rasa suka dari orang lain, dan tetap setia dengan teman berarti siswa akan berjuang dalam mempertahankan hubungannya dengan orang lain.

Muray (Ekinasmara, 2013) menyatakan adanya kebutuhan afiliasi akan memotivasi individu untuk berteman serta akan cenderung mempertahankan hubungan yang telah terjalin dengan orang lain, hal ini dapat dilihat dari sikap hangat, terbuka, dan menjaga perasaan orang lain. Selanjutnya dorongan berafiliasi ada disebabkan karena manusia sebagai makhluk sosial yang memiliki berbagai keutuhan yang harus dipenuhi agar kehidupannya berjalan lancar (Yunairrahmah, 2014). Siswa yang mampu menampilkan sikap hangat, terbuka, dan merasa aman akan mempunyai rasa percaya diri yang tinggi serta bebas dalam menyatakan pikiran, perasaan dan mampu untuk berkreasi (Ifdil, 2013).

Berdasarkan penelitian Rinjani \& Firmanto (2013) mengenai kebutuhan afiliasi ditemukan bahwa terdapat $46 \%$ remaja yang memiliki kebutuhan afiliasi rendah. Selanjutnya penelitian yang dilakukan oleh Aridarmaputri, Akbar \& Yunairrahmah pada indikator kebutuhan afiliasi berada pada kategori sedang $(71,11 \%)$.

Kemudian, pada penelitian Anggraini hasil penelitian tersebut pada indikator kebutuhan afiliasi berada pada kategori sedang dengan persentase $86,9 \%$. Penelitian lain yang dilakukan oleh Ekinasmara $\&$ Laksmiwati hasil penelitian pada indikator kebutuhan afiliasi berada pada kategori rendah. Hal ini dilihat dari kontribusi kebutuhan afiliasi terhadap konsep diri dan penyesuaian sosial dengan persentase 60,94\% sering merasa tidak percaya diri/minder saat bergaul dengan teman, 10,16\% siswa mengaku tidak punya banyak teman, $12,50 \%$ merasa tidak diterima dalam pergaulan, 14,84\% merasa dikucilkan oleh teman, $42,97 \%$ siswa mengaku memiliki masalah dengan teman tertentu. Sebanyak, 35,94\% mengaku menjaga jarak dengan teman tertentu, 24,22\% merasa kesulitan membaur dengan teman-temannya.

Berdasarkan pengamatan di SMP Negeri 2 Padang, ditemukan beberapa orang siswa kurang mampu dalam bekerjasama dan menyukai bekerja secara individual, hal ini terlihat ketika siswa diberikan tugas kelompok, ada beberapa orang siswa memilih untuk mengerjakan tugas sendiri. Adanya siswa yang menyakiti perasaan temannya, terlihat ketika ada siswa yang mengejek temannya. Beberapa orang siswa ketika istirahat memilih untuk makan sendiri dibandingkan bergabung dengan teman. Adanya siswa yang kurang diterima oleh kelompok kelasnya, hal ini terlihat pada saat siswa memilih untuk tidak duduk bersama dengan teman kelasnya serta mengucilkan teman. Beberapa orang siswa mengalami hambatan dalam menjalin kedekatan interpersonal, hal ini terlihat ketika jam istirahat ia lebih memilih untuk menghabiskan waktu sendirian. Selanjutnya berkaitan dengan dukungan sosial yang diterima, ada beberapa siswa yang tidak mendapatkan dukungan sosial dari temannya, misalnya diperolok saat memberi pertanyaan.

Untuk membantu siswa mencapai kebutuhan afiliasi tanpa mengabaikan tugas perkembangan dirinya, diperlukan bantuan guru bimbingan dan konseling/ konselor sekolah (guru BK/ konselor). Selanjutnya pelayanan bimbingan dan konseling berfungsi untuk membantu kelompok individu dalam 
memahami diri dan lingkungan, mencegah masalah yang mengganggu perkembangannya, menyelesaikan masalah, mengembangkan potensinya (Sukmawati, Neviyarni, Syukur \& Said, 2013). Tohirin (2013:26) menyatakan bimbingan dan konseling merupakan proses bantuan yang diberikan oleh seorang tenaga ahli (konselor) kepada individu (konseli) yang dilakukan secara langsung atau melalui tatap muka agar konseli dapat mengetahui masalahnya serta dapat memecahkan masalahnya sendiri. Peranan guru BK/ konselor dalam hal ini ialah memberikan informasi kepada siswa mengenai kebutuhan dan tugas perkembangannya serta memberikan pemahaman kepada siswa untuk terwujudnya kehidupan yang efektif, serta terwujudnya tugas perkembangan dirinya yang optimal dan terpenuhi kebutuhannya. Hal ini dilakukan dengam memberikan layanan informasi. Layanan informasi merupakan layanan yang memberikan individu pengetahuan tentang fakta baik bidang pribadi, sekolah, pekerjaan dan hubungan sosial (Fitri, Neviyarni, \& Ifdil, 2016) Untuk itu guru BK/ konselor sekolah membantu siswa untuk mencapai kebutuhan afiliasinya dan mengembangkan dirinya, dengan terwujudnya tugas perkembangannya.

\section{METODE}

Jenis penelitian yang digunakan dalam penelitian ini ialah deskriptif. Penelitian deksriptif adalah salah satu penelitian kuantitatif yang bertujuan untuk mendeskripsikan secara sistematis, aktual dalam memberikan jawaban terhadap suatu masalah atau mencoba menggambarkan fenomena secara detail (Yusuf, 2014:61). Penelitian ini bertujuan mengungkapkan kebutuhan afiliasi siswa di SMP Negeri 2 Padang dengan jumlah sampel 271 siswa dengan menggunakan teknik pengambilan sampel stratified random sampling. Stratified random sampling merupakan salah satu teknik pengambilan sampel dengan membagi sampel yang memiliki tingkat (Yusuf, 2014). Intrumen yang digunakan adalah inventori kebutuhan afiliasi dengan reliabilitas 0,725. Analisis data yang digunakan dalam penelitian ini menggunakan teknik analisis persentase.

\section{HASIL DAN PEMBAHASAN}

Berdasarkan pengolahan data yang telah dilakukan, maka data hasil penelitian ini di jelaskan dan dianalisis sesuai dengan tujuan penelitian, yaitu mendeskripsikan kondisi kebutuhan afiliasi siswa berdasarkan aspek mendekatkan diri, bekerjasama, membuat senang, mencari afeksi, dan tetap setia dengan teman.

Deskripsi data kebutuhan afiliasi siswa berdasarkan aspek mendekatkan diri

Kebutuhan afiliasi siswa SMP Negeri 2 Padang berdasarkan aspek mendekatkan diri dapat dilihat pada tabel di bawah ini.

Tabel. Kebutuhan Afiliasi Siswa Sub Variabel Mendekatkan diri (n=271)

\begin{tabular}{llrrr}
\hline \multicolumn{1}{c}{ Kategori } & \multicolumn{1}{c}{ Skor } & f & \multicolumn{1}{c}{$\%$} \\
\hline Sangat Tinggi (ST) & $\geq 20$ & 36 & 13.3 \\
Tinggi (T) & $\geq 18-19$ & 51 & 18.8 \\
Sedang (S) & $\geq 15-17$ & 124 & 45.8 \\
Rendah (R) & $\geq 12-14$ & 50 & 18.5 \\
Sangat Rendah (SR) & $\leq 11$ & 10 & 3.7 \\
\hline & & 271 & 100.0 \\
\hline
\end{tabular}

Berdasarkan tabel, dapat diketahui bahwa sub variabel mendekatkan diri kebutuhan afiliasi siswa, $13,3 \%$ berada pada kategori sangat tinggi, 18,8\% berada pada kategori tinggi, 45,8\% berada pada kategori sedang, $18,5 \%$ berada pada kategori rendah, dan 3,7\% berada pada kategori sangat rendah. Secara keseluruhan mendekatan diri kebutuhan afiliasi siswa berada pada kategori sedang.

Hal ini mengungkapkan kebutuhan mendekatkan diri dengan orang lain khususnya teman masih belum terpenuhi. Artinya siswa masih kurang memiliki kebutuhan untuk berteman dengan siapa saja serta kurang dalam menciptakan kedekatan yang baik dengan teman. Mendekatkan diri mengarah kepada 
kedekatan individu dengan orang lain dengan menunjukkan perasaan dan emosi untuk menciptkan kedekatan dengan orang lain (Ulfah,2011:292). Kenyataan yang ditemukan masih ada siswa yang belum terpenuhi kebutuhan mendekatkan diri, siswa masih belum mampu membina kedekatan dengan temannya. Idealnya siswa mampu mendekatkan diri dengan orang lain. Kebutuhan mendekatkan diri dengan orang lain ini akan terlihat dari bagaimana siswa memiliki kesadaran akan hubungan baik dengan siapa aja serta mampu mendekatkan diri dengan orang lain.

Deskripsi data kebutuhan afiliasi siswa berdasarkan aspek bekerjasama

Kebutuhan afiliasi siswa SMP Negeri 2 Padang berdasarkan aspek bekerjasama dapat dilihat pada tabel dibawah ini.

Tabel. Kebutuhan Afiliasi Siswa Sub Variabel Bekerjasama (n=271)

\begin{tabular}{llrrr}
\hline \multicolumn{1}{c}{ Kategori } & \multicolumn{1}{c}{ Skor } & f & \multicolumn{1}{c}{$\%$} \\
\hline Sangat Tinggi (ST) & $\geq 20$ & 34 & 12.5 \\
Tinggi (T) & $\geq 17-19$ & 77 & 28.4 \\
Sedang (S) & $\geq 14-16$ & 99 & 36.5 \\
Rendah (R) & $\geq 11-13$ & 43 & 15.9 \\
Sangat Rendah (SR) & $\leq 10$ & 18 & 6.6 \\
\hline \multicolumn{2}{r}{} & & 271 & 100.0 \\
\hline
\end{tabular}

Berdasarkan tabel, dapat diketahui bahwa sub variabel bekerjasama kebutuhan afiliasi siswa, 12,5\% berada pada kategori sangat tinggi, 28,4\% berada pada kategori tinggi, 36,5\% berada pada kategori sedang, $15,9 \%$ dikategorikan rendah dan 6,6\% dikategorikan sangat rendah. Secara keseluruhan bekerjasama kebutuhan afiliasi siswa sebagian siswa berada pada kategori sedang.

Hal ini berarti sebagian besar siswa masih kurang terpenuhi kebutuhan akan bekerjasama, siswa masih kurang butuh bersama orang lain serta masih kurang butuh mengerjakan tugas bersama-sama. Seharusnya menurut pangewa (2004:94) individu yang kebetuhan afiliasinya baik cenderung lebih senang untuk bekerja sama dalam melakukan sesuatu. siswa telah mampu bertukar pendapat, merespon teman serta mampu menyelesaikan persoalan secara bersama-sama dalam memenuhi kebutuhan afiliasi.

Deskripsi data kebutuhan afiliasi siswa berdasarkan aspek membuat senang

Kebutuhan afiliasi siswa SMP Negeri 2 Padang berdasarkan aspek bekerjasama dapat dilihat pada tabel dibawah ini.

Tabel. Kebutuhan Afiliasi Siswa Sub Variabel Membuat Senang

\begin{tabular}{llrrr}
\hline \multicolumn{1}{c}{ Kategori } & & Skor & \multicolumn{2}{c}{$\%$} \\
\hline Sangat Tinggi (ST) & $\geq 29$ & 24 & 8.9 \\
Tinggi (T) & $\geq 25-28$ & 71 & 26.2 \\
Sedang (S) & $\geq 21-24$ & 110 & 40.6 \\
Rendah (R) & $\geq 17-20$ & 44 & 16.2 \\
Sangat Rendah (SR) & $\leq 16$ & 22 & 8.1 \\
\hline \multicolumn{2}{r}{} & Jumlah & 271 & 100.0 \\
\hline
\end{tabular}

Berdasarkan tabel, dapat diketahui bahwa sub variabel membuat senang kebutuhan afiliasi siswa, $8,9 \%$ berada pada kategori sangat tinggi, 26,2\% berada pada kategori tinggi, 40,6\% berada pada kategori sedang, $16,2 \%$ berada pada kategori rendah dan $8,1 \%$ berada pada kategori sangat rendah. Secara 
keseluruhan kebutuhan afiliasi siswa yang menunjukkan membuat senang sebagian besar berada pada kategori sedang.

Artinya rata-rata siswa masih kurang terpenuhi kebutuhan membuat senang, ini terjadi karena ratarata siswa masih kurang kebutuhan untuk menyenangkan teman serta kurang peduli terhadap teman. Idelanya menurut pangewa (2004:94) individu yang memiliki kebutuhan afiliasi akan lebih mementingkan kepentingan antar pribadi dari pada dirinya. Kenyataanya dilapangan masih ada siswa yang lebih mementingkan kepentingan pribadi dari pada kepentingan antar pribadi, seperti masih ada yang menjahili teman untuk kesenangannya.

Deskripsi data kebutuhan afiliasi siswa berdasarkan aspek mencari afeksi

Kebutuhan afiliasi siswa SMP Negeri 2 Padang berdasarkan aspek mencari afeksi dapat dilihat pada tabel dibawah ini.

Tabel . Kebutuhan Afiliasi Siswa Sub Variabel Mencari Afeksi

\begin{tabular}{lcccc}
\hline \multicolumn{1}{c}{ Kategori } & & Skor & F & $\%$ \\
\hline Sangat Tinggi (ST) & $\geq 24$ & 21 & 7.7 \\
Tinggi (T) & $\geq 21-23$ & 94 & 34.7 \\
Sedang (S) & $\geq 17-20$ & 82 & 30.3 \\
Rendah (R) & $\geq 14-16$ & 51 & 18.8 \\
Sangat Rendah (SR) & $\leq 13$ & 23 & 8.5 \\
\hline \multicolumn{2}{l}{} & Jumlah & 271 & 100.0 \\
\hline
\end{tabular}

Berdasarkan tabel, dapat diketahui bahwa sub variabel mencari afeksi kebutuhan afiliasi siswa, $7,7 \%$ berada pada kategori sangat tinggi, 34,7\% berada pada kategori tinggi, 30,3\% berada pada kategori sedang, $18,8 \%$ berada pada kategori rendah dan $8.5 \%$ berada pada kategori sangat rendah. Secara keseluruhan kebutuhan afiliasi siswa yang menunjukkan mencari afeksi sebagian besar berada pada kategori tinggi.

Hal ini mengungkapkan kebutuhan mencari afeksi siswa tinggi. artinya kebutuhan mencari afeksi sebagian siswa telah terpenuhi. Afeksi pada prinsipnya merupakan perasaan untuk disukai dan dicintai oleh orang lain khususnya teman (Robi, 2013:10). Artinya perasaan untuk dicintai disayangi, dan perhatian orang lain siswa tinggi, seperti siswa telah mampu menghargai teman. Walau masih ditemukan siswa yang belum terpenuhi kebutuhan mencari afeksi. Idealnya siswa memiliki kebutuhan akan disukai, disayangi, dan diperhatikan orang lain. Individu yang mencari afeksi akan mengharapkan pendapat baik dari orang lain dan peka terhadap penolakan dari orang lain (Hall \& Lindzey, 2004:266).

Deskripsi data kebutuhan afiliasi siswa berdasarkan aspek tetap setia dengan teman

Kebutuhan afiliasi siswa SMP Negeri 2 Padang berdasarkan aspek tetap setia dengan teman dapat dilihat pada tabel dibawah ini. 
Tabel. Kebutuhan Afiliasi Siswa Sub Variabel Tetap Setia pada Teman

\begin{tabular}{lcrrr}
\hline \multicolumn{1}{c}{ Kategori } & Skor & F & \multicolumn{2}{c}{$\%$} \\
\hline Sangat Tinggi (ST) & $\geq 38$ & 15 & 5.5 \\
Tinggi (T) & $\geq 32-37$ & 84 & 31.0 \\
Sedang (S) & $\geq 27-31$ & 99 & 36.5 \\
Rendah (R) & $\geq 21-26$ & 55 & 20.3 \\
Sangat Rendah (SR) & $\leq 20$ & 18 & 6.6 \\
\hline \multicolumn{2}{r}{} & & 271 & 100.0 \\
\hline
\end{tabular}

Berdasarkan tabel, dapat diketahui bahwa sub variabel tetap setia dengan teman kebutuhan afiliasi siswa, 5,5\% berada pada kategori sangat tinggi, 31\% berada pada kategori tinggi, 36,5\% berada pada kategori sedang, 20,3\% berada pada kategori rendah dan 6,6\% berada pada kategori sangat rendah. Secara keseluruhan kebutuhan afiliasi siswa yang menunjukkan tetap setia pada teman sebagian besar berada pada kategori sedang.

Hal ini berarti bahwa rata-rata siswa masih kurang terpenuhi kebutuhan akan tetap setia dengan teman, ini terjadi karena sebagain siswa belum mampu dan belum sadar untuk menunjukkan sikap setia pada teman. Hal ini dikarenakan kebutuhan remaja untuk diakui, dihargai dan tergantung pada kelompok sehingga menyebabkan remaja mempunyai rasa takut kehilangan yang langsung membuat untuk setia terhadap teman (Rinjani \& Firmanto, 2013:81). Kenyataannya masih ada siswa yang belum menepati janji. Idealnya siswa akan merasa senang apabila di berikan pujian, mendapat penghargaan serta menepati janji. Individu yang memiliki kebutuhan afiliasi akan menunjukkan sikap setia dengan teman, hal ini dikarenakan sifat alami individu yang takut kehilangan teman (Khasanah, 2015).

\section{KESIMPULAN}

Berdasarkan hasil penelitian yang telah dilakukan dapat disimpulkan, sebagai berikut: 1) kebutuhan afiliasi siswa berdasarkan aspek mendekatkan diri sebagian siswa berada pada kategori sedang dengan persentase $45,8 \%, 2$ ) kebutuhan afiliasi siswa berdasarkan aspek bekerjasama sebagian siswa berada pada kategori sedang dengan persentase $36,5 \%, 3$ ) kebutuhan afiliasi siswa berdasarkan aspek membuat senang sebagian siswa berada pada kategori sedang dengan persentase 40,6\%, 4) kebutuhan afiliasi siswa berdasarkan aspek mencari afeksi sebagian siswa berada pada kategori tinggi dengan persentase 34,7\%, 5) kebutuhan afiliasi siswa berdasarkan aspek tetap setia pada teman sebagian siswa berada pada kategori sedang dengan persentase 36,5\%. Artinya kebutuhan afiliasi siswa di SMP Negeri 2 Padang masih kurang baik, walau sebagian siswa telah memenuhi kebutuhan afiliasinya. Untuk itu diperlukan peran guru BK dalam membantu siswa memenuhi kebutuhan afilisinya. Guru BK dapat memberikan layanan informasi berkaitan dengan kebutuhan afiliasi seperti materi mengenai membina keakraban dengan teman, melakukan layanan konseling individual bagi siswa yang masih rendah kebutuhan afiliasinya, serta dapat melakukan layanan bimbingan kelompok dalam menciptakan hubungan yang akrab dengan anggota kelasnya.

\section{DAFTAR RUJUKAN}

Anggraini, J. (2016). Hubungan Antara Kebutuhan Afiliasi Dengan Asertivitas Pada Peserta Didik Di Madrasah Aliyah Patra Mandiri Palembang. Skripsi. Tidak diterbitkan. Palembang UIN Raden Fatah.

Alizamar, A., Ifdil, I., Fadli, R. P., Erwinda, L., Zola, N., \& Churnia, E. \& Rangka, IB (2018). The Effectiveness of Hypnotherapy in Reducing Stress Levels. Addictive Disorders \& Their Treatment.

Annisa, D. F., \& Ifdil, I. (2016). Konsep Kecemasan (Anxiety) pada Lanjut Usia (Lansia). Konselor, 5(2), 93-99.

Ardi, Z., Ibrahim, Y., \& Said, A. (2012). Capaian Tugas Perkembangan Sosial Siswa dengan Kelompok Teman Sebaya dan Implikasinya Terhadap Program Pelayanan Bimbingan dan Konseling, 1(1). 
Effectiveness of Hypnotherapy in Reducing Stress Levels. Addictive Disorders \& Their Treatment.

Barseli, M., Ifdil, I., \& Nikmarijal, N. (2017). Konsep Stres Akademik Siswa. Jurnal Konseling dan Pendidikan, 5(3), 143-148.

Ekinasmara, F. P. (2013). Hubungan Konsep Diri Dan Kebutuhan Berafiliasi Dengan Penyesuaian Sosial Siswa SMPN 8 Madiun. Character: Jurnal Penelitian Psikologi., 1(2). Retrieved from https://www.google.co.id/url?sa=t\&rct=j\&q=\&esrc=s\&source=web\&cd=1\&cad=rja\&uact=8\&ved =0ahUKEwipqfuS9M3YAhWFl5QKHdhIDcoQFgglMAA\&url=http\%3A\%2F\%2Fjurnalmahasis wa.unesa.ac.id\%2Farticle\%2F3470\%2F17\%2Farticle.pdf\&usg=AOvVaw3LuQoqk7MQqXIURb5 vXYB0

Fitri, Neviyarni, Ifdil. (2016). Efektivitas Layanan Informasi dengan Menggunakan Metode Blended Learning untuk Meningkatkan Motivasi Belajar Siswa, 2, 84-92.

Fitri, E., Zola, N., \& Ifdil, I. (2018). Profil Kepercayaan Diri Remaja serta Faktor-Faktor yang Mempengaruhi. JPPI (Jurnal Penelitian Pendidikan Indonesia), 4(1), 1-5.

Ifdil, I. (2013). Konsep Dasar Self Disclosure Dan Pentingnya Bagi Mahasiswa Bimbingan Dan Konseling. PEDAGOGI | Jurnal Ilmiah Ilmu Pendidikan, 13(1), 110-117.

Ifdil, I., Denich, A. U., \& Ilyas, A. (2017). Hubungan Body Image dengan Kepercayaan Diri Remaja Putri. Jurnal Kajian Bimbingan Dan Konseling, 2(3), 107-113. https://doi.org/10.17977/um001v2i32017p107

Karneli, Y. (2018). Upaya Guru BK untuk Mengentaskan Masalah-Masalah Perkembangan Remaja dengan Pendekatan Konseling Analisis Transaksional, 2(1).

Khaira, I., Firman, \& Neviyarni, S. (2017). Efektivitas Pendekatan Rational Emotive Behavior Therapy (REBT) dalam Meningkatkan Penyesuaian Sosial Anak Asuh di Panti Asuhan Wira Lisna Padang. Jurnal Bikotetik, (1), 1-7.

Khasanah, S. (2015). Hubungan antara Kebutuhan Afiliasi dengan Keterbukaan Diri pada Remajapengguna Blackberry Messenger (BBM), 1-10. Retrieved from http://repository.uinsuska.ac.id/id/eprint/6708

Purwadiningsih. (2016). Studi Komparasi Tentang Motif Afiliasi Pada Siswa Yang Orang Tuanya Single Parent Dengan Yang Lengkap Pada Siswa Kelas Ii Smk Negeri 1 Wonosegoro, 1-13. Retrieved from http://jurnal-mahasiswa.unisri.ac.id/index.php/fkipbk/article/viewFile/306/249

Reski, N., Taufik, T., \& Ifdil, I. (2017). Konsep diri dan kedisiplinan belajar siswa. Jurnal EDUCATIO: Jurnal Pendidikan Indonesia, 3(2), 85-91.

Sandra, R., \& Ifdil, I. (2015). Konsep Stres Kerja Guru Bimbingan dan Konseling. Jurnal EDUCATIO: Jurnal Pendidikan Indonesia, 1(1), 80-85.

Sukmawati, Neviyarni, Syukur \& Said. (2013). Peningkatan Hasil Belajar melalui Dinamika Kelompok dalam Perkuliahan Pengajaran Psikologi dan Bimbingan Konseling (PPBK). Universitas Negeri Padang, XIII(2), 10-18.

Taufik, Ifdil \& Ardi, Z. (2013). Kondisi Stress Akademik Siswa SMA Negeri di Kota Padang. Jurnal Konseling dan Pendidikan. 1(2), 143-150.

Thanoesya, R., Syahniar, S., \& Ifdil, I. (2016). Konsep Diri dan Optimisme Mahasiswa dalam Proses Penulisan Skripsi. JPPI (Jurnal Penelitian Pendidikan Indonesia), 2(2), 58-61.

Ulfah, T. A. (2011). Gaya Hidup Hedonis Pada Mahasiswa Yang Mengunjungi Tempat Hiburan Malam Ditinjau Dari Motif Afiliasi. Jurnal Fakultas Psikologi Universitas Semarang.

Wardi, R., \& Ifdil, I. (2016). Stress Conditions in Students Completing Thesis. GUIDENA: Jurnal Ilmu Pendidikan, Psikologi, Bimbingan dan Konseling, 6(2), 190-194.

Yunairrahmah, A. \& A. \&. (2014). Pengaruh Jejaring Sosial Terhadap Kebutuhan Afiliasi Remaja Di Program Studi Psikologi Fakultas Kedokteran Universitas Lambung Mangkurat. Journal of Psychology, 1-6. Retrieved from http://ppjp.unlam.ac.id/journal/index.php/ecopsy/article/download/1937/1684

Yusuf, A. M. (2013). Metode Penelitian. Padang. UNP Press.

Zola, N., Fadli, R. P., \& Ifdil, I. (2018). Chromotherapy to reducing stress. 